\title{
New Method for Synthesis of Coatings of Molybdenum, Tungsten, Their Carbides and Composites
}

\author{
Rhushikesh V. Godbole ${ }^{1}$, Mahendra A. More ${ }^{1}$, Anil S. Gupte ${ }^{2}$, Vijay P. Godbole ${ }^{1 *}$ \\ ${ }^{1}$ Center for Nano-Materials and Quantum Systems (CNQS), Department of Physics, University of Pune, Pune, India \\ ${ }^{2}$ Technical Director, Poona Shims Pvt. Ltd., Pune, India \\ Email: *vijay.godbole@rediffmail.com
}

Received November 30, 2012; revised January 6, 2013; accepted January 24, 2013

Copyright (c) 2013 Rhushikesh V. Godbole et al. This is an open access article distributed under the Creative Commons Attribution License, which permits unrestricted use, distribution, and reproduction in any medium, provided the original work is properly cited.

\begin{abstract}
In this paper we report, for the first time, a new approach for synthesis of high quality faceted microcrystalline coatings of molybdenum (Mo), tungsten (W), their carbides and composites. These studies are carried out using Hot Filament Chemical Vapor Deposition (HF-CVD) method wherein parent materials (Mo and/or W) are taken in the form of wires $\left(\sim 0.5 \mathrm{~mm}\right.$ dia) and are heated to a high temperature $\left(\mathrm{T}_{\mathrm{F}} \sim 1500-2000 \mathrm{C}\right)$, in ambient of "oxygen $\left(\mathrm{O}_{2}\right)$ diluted hydrogen $\left(\mathrm{H}_{2}\right)$ gas”. Due to high filament temperature $\left(\mathrm{T}_{\mathrm{F}}\right)$, a series of pyrolytic reactions take place. Firstly, the gasification of wire material (Mo and/or W) occurs in the form of its oxide. The oxide molecules reach the substrate which is kept underneath the filament assembly. Secondly, molecular hydrogen gets dissociated into atomic hydrogen and subsequently reaches the substrate to react with oxide molecules, finally leading to the precipitation of a pure metal. This method can also be used, in situ, to convert metallic coatings into their carbides and/or composites. The method offers many other attractive features, which can not be rendered by the conventional CVD/PVD methods. The results are discussed in terms of temperature induced "Red-ox" reactions.
\end{abstract}

Keywords: CVD Coatings; Pyrolysis; Ceramics; Refractories

\section{Introduction}

Since materials play a central role in different technologies, there has been a tremendous increase in the activity of "materials research". In view of a new trend of "collapsing dimentions" in modern technologies, the subject of "materials coatings" has received a prime importance to form new materials. Novelty of these new materials refers to a multi-parametric restrictions on different physical/chemical properties, so as to be suitable in given type of application/s. To design and develop such special coatings, a major imoprtance has also been to the methods of fabrication of such coatings. Over last few years, substantial research efforts have been and are being expended in this subject. Various types of newer physical/ chemical methods have been devised for synthesis of coatings of various types. On one hand, some of these methods are now matured enough to routinely achieve the objective, while on the other hand newer methods/ concepts are still being proposed to synthesize required types of materials coatings.

The refractory metals particularly molybdenum (Mo),

*Corresponding author. tungsten (W) and also their compounds viz. carbides, oxides etc. form a special class of "materials "coatings. These coatings exhibit properties useful for many technological applications [1-3]. In view of their high melting points, these materials are thermally very stable and hence can be used for high temperature applications [4]. Because of high erosion resistance, these coatings are useful for protection against high-energy radiations [5]. The feature of high "chemical corrosion resistance" makes them useful in corrosion science. These materials coatings also exhibit lower diffusivities towards different atomic species. So coatings of these materials can be used as diffusion barriers [6,7] as well as thermal barriers [8]. The resistance to elecro-migration phenomenon as well as appropriate electrical resitivities makes them useful for device technologies for fabrication of schottky barriers, interconnect lines and back contacts to solar cells etc. [9-11]. These materials also show enhanced "electron emission" and hence these are useful for developments of electron emission devices [12]. The higher values of modulus and hardness attract their applications in wear control in mechanical industry [13-16]. The oxides of these materials have applications for gas sensing 
[17] as well as electro chromic devices [18,19].

Because of high melting points, however, conventional resistive evaporation method is not possible for the fabrication of coatings of these materials. The conventional CVD method and the sputtering method can be used but both these methods pose problems such as 1) requirement of hazardous organic precursors; 2) limitations on area of deposition; 3) limited growth rates; 4) complicated system set up etc. A need is, thus, felt to use newer methodology which could avoid these problems and yield easier and efficient fabrication of thicker, high quality coatings of these materials.

In this brief report, we describe for the first time, a simple and novel approach to synthesize high quality, faceted, micro-crystalline coatings of molybdenum (Mo), tungsten (W), their carbides and composites. This method is primarily based upon "Hot Filament Chemical Vapor Deposition (HF-CVD)" technique. This new method has many attractive features, which are not rendered by conventional CVD/PVD methods. The present method is 1) very simple and efficient; 2) it offers an easy control on different process parameters which could lead to a different morphological features of the resultant coatings; 3 ) since the method is based on HF-CVD technique, it requires a simple system set up. More importantly; 4) the method does not require use of any hazardous chemical precursors; 5) the method renders much larger growth rates ( typically more than $\sim 10 \mu \mathrm{m} /$ hour or even higher) than those offered by conventional CVD/ PVD methods and hence; 6) it is possible to achieve much thicker coatings over practicable time scales. Finally; 7) the method is capable of obtaining coatings on much larger areas. In this paper, we have demonstrated that it is just a question of appropriately controlling the process parameters, to achieve all these objectives.

\section{Experimental}

The HF-CVD set up $[20,21]$ used in the present studies has been indegeniously designed and developed in our laboratory. It consists of a water cooled stainless steel chamber (size $\sim 30 \mathrm{~cm}$ dia $\times 25 \mathrm{~cm}$ height) having a number of ports to mount different accessory components such as high current feed throughs for filament heating, a gas mixing unit and input gas lines, the filament and the substrate holders along with controls for $\mathrm{X}-\mathrm{Y}$ movement and rotational movement etc. The small pieces (typical size $\sim 10 \mathrm{~mm} \times 10 \mathrm{~mm}$ ) of $<100>$ and $<111>$ silicon (Si), high purity (99.99\%) polycrystalline alumina $\left(\alpha-\mathrm{Al}_{2} \mathrm{O}_{3}\right)$, copper (Cu), tool steel (TS), stainless steel (SS) etc. are used as substrates. The samples are cleaned by using standard procedures and are used for deposition experiments. The pure (99.99\%) gases such as oxygen $\left(\mathrm{O}_{2}\right)$ and/or methane $\left(\mathrm{CH}_{4}\right)$ are diluted in excess amount of hydrogen $\left(\mathrm{H}_{2}\right)$ and/or argon ( $\mathrm{Ar}$ ) gas and then flown over the heated filament assembly of molybdenum (Mo) and/or tungsten (W) wires. For the deposition of pure metal coating, the gas composition $\mathrm{H}_{2}: \mathrm{O}_{2}=100: 3 \mathrm{sccm}$ is used. The filament temperatures are adjusted, using Pyrometer, over the range $1500^{\circ} \mathrm{C}-2000^{\circ} \mathrm{C}$ by passing a suitable amount of current. The gas flow rates are controlled by using mass flow controllers (MFCs). The microprocessor based combination of "auto-throttle valve and a Capacitance diaphram gauge" is used to control the chamber pressure. It is typically adjusted over the range 20 - 100 Torr depending upon the particular type of experiment. The deposition time is varied over $10 \mathrm{~min}-120 \mathrm{~min}$. Subsequent to depostion, the specimens are characterized by using methods such as conventional and glancing angle X-ray diffraction (XRD), field emmision scanning electron microscopy (FE-SEM), energy dispersive analysis of $\mathrm{X}$-rays (EDX), Resistivity measurements etc. to get an information on morphological, structural, and compositional features of resultant coatings. The studies using additional microscopic characterization tools such as transmission electron microscopy (TEM), atomic force microscopy (AFM), scanning tunneling Microscopy (STM), X-ray photo-electron spectroscpy (XPS), nanoindentation are also in progress in our laboratory and these results will be published separatly.

\section{Results and Discussion}

In a given deposition experiment, the different types of substrates are kept "side-by-side" on the substrate holder so that these get processed at almost identical processing conditions. So it is meaningful to compare the morphologies of coatings, on different types of substrates.

Figure 1 shows the FE-SEM micrographs, at different magnifications, corresponding to coatings obtained using Mo-filament (Figures 1(a) and (b)) and using W-filament (Figures 1(c) and (d)) on <111> silicon substrates. These coatings are obtained using nominally adjusted process parameters, viz. the composition of gas mixture $\mathrm{H}_{2}: \mathrm{O}_{2}=100: 10 \mathrm{sccm}$, flow rate of gas mixture $110 \mathrm{sccm}$, the filament temperature $\left(\mathrm{T}_{\mathrm{F}}\right)=1800 \mathrm{C}$, the substrate temperature $\left(T_{S}\right)=500 \mathrm{C}$, the chamber pressure $=30$ Torr, and the deposition time $20 \mathrm{~min}$. As can be seen from these micrographs, both the types of coatings exhibit a cauliflower type of morphology. The EDX and glancing angle X-ray diffraction measurements are also carried out on both these types of coatings. These results exhibit simillar results in the context of structural and compositional features. The EDX measurements, as shown in Figure 1(e), refers to the Mo-coatings which reveals that the coating consists of $\sim 30$ at $\%$ of oxygen and $\sim 70$ at $\%$ of molybdenum. While the glancing angle X-ray diffraction result, as shown in Figure 1(f), for coating obtained using $\mathrm{W}$-filament reveals formation of highly disordered (very broad 


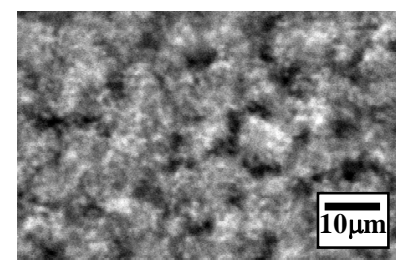

(a)

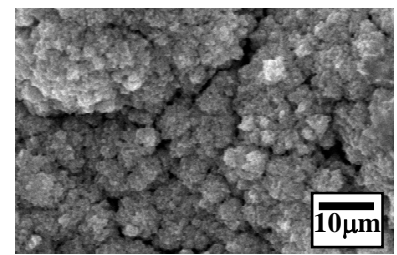

(c)

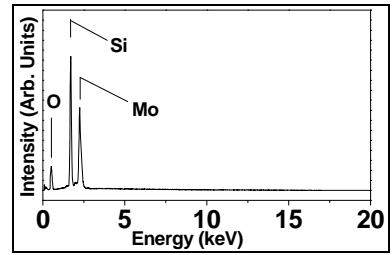

(e)

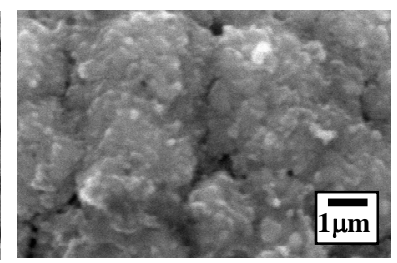

(b)

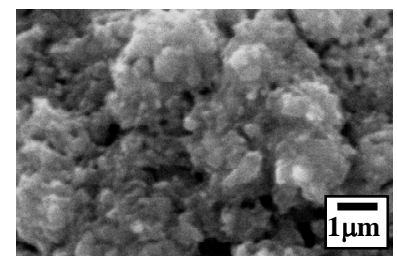

(d)

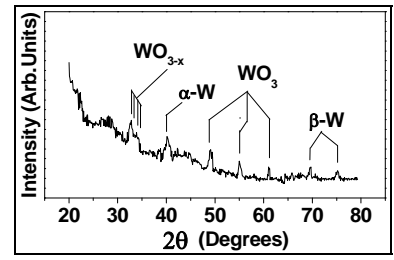

(f)
Figure 1. FE-SEM results, at different magnifications, for (a) and (b) Mo-coating, while (c) and (d) for W-film on $<111>$ Si substrates, at nominally adjusted processing conditions. The corresponding (e) EDX result for Mo film and (f) glancing angle $\mathrm{X}$-ray diffraction result for $\mathrm{W}$-film.

diffraction peaks) $\mathrm{WO}_{3-\mathrm{x}}, \alpha$-tungsten and $\beta$-tungsten phases [22].

To achieve high quality coatings, the filament temperature $\left(T_{F}\right)$ was increased to $1900 \mathrm{C}$, the substrate temperature $\left(\mathrm{T}_{\mathrm{S}}\right)$ was also increased to $\sim 800 \mathrm{C}$, the composition of gas used $\mathrm{H}_{2}: \mathrm{O}_{2}=100: 2 \mathrm{sccm}$. The chamaber pressure and deposition time kept unaltered (30 Torr and $20 \mathrm{~min}$, respectively, but these can also be changed. The variation of these parameters results in variation in the thickness of the film only). These happen to be the optimized conditions for getting high quality, faceted coatings of Mo and W on Si (Figure 2) and on Alumina substrates (Figure 3). As can be seen from the SEM overview micrographs, the coverage of Mo-coating (shown in Figure 2(a)) and W-coating (shown in Figure 2(c)) is very uniform throughout the sample area. The magnified FE-SEM views are shown in Figure 2(b) (for Mo coating) and Figure 2(d) (for W coating). These results reveal that in both the cases the particles are very well faceted, although, there is a difference in the morphology. The Mo-particles are of "hexagonal" shaped while W-particles are mainly of "three and four sided pyramidal shapes". This seems to be very interesting because in both the cases we have $<111>$ Si substrate and both metals (Mo and W) have cubic BCC-type lattice with almost the same lattice parameters (3.14 $\AA$ for Mo

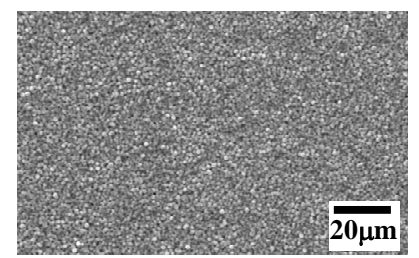

(a)

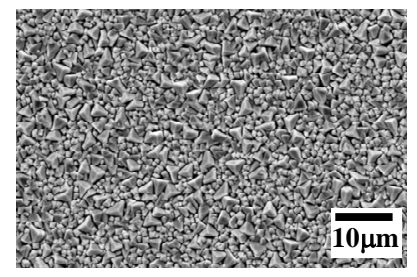

(c)

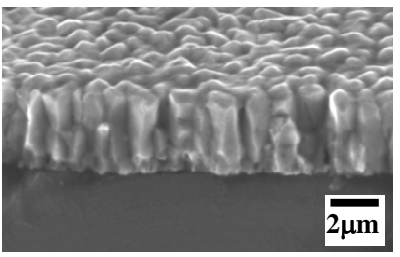

(e)

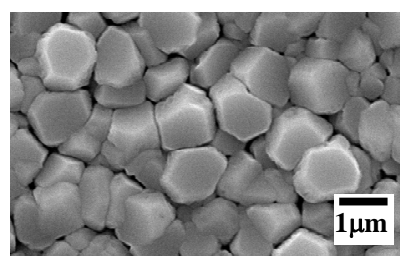

(b)

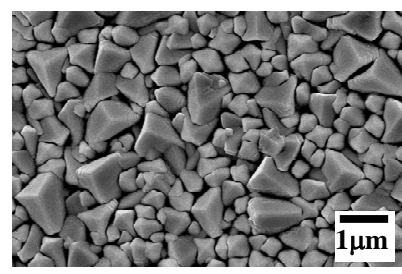

(d)

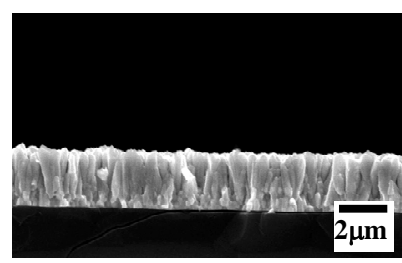

(f)
Figure 2. Typical FE-SEM results, corresponding to (a) and (b) high quality Mo-coating, (c) and (d) correspond to high quality W-coating on $<111>\mathrm{Si}$ substrates. The cross-sectional views shown in (e) and (f) refer to Mo-coating and W-coating, respectively.

and $3.16 \AA$ for $\mathrm{W}$ ). This morphological difference remains the same even in the case of Alumina substrate (FE-SEM results are shown in Figure 3). There is also a difference in the particle size-distribution. In Mo-case there is almost no size-distribution (uniform particle size of $\sim 0.8 \mu \mathrm{m}$ ) while for $\mathrm{W}$-case the particle size varies over $\sim 0.3 \mu \mathrm{m}$ to $0.9 \mu \mathrm{m}$. The adhesion of coatings found is to be excellent as qualitatively tested by "Scoch-tape method". Figures 2(e) and (f) show cross-sectional SEM micrographs for Mo-coating and W-coating, respectively. In both the cases, the growth of coatings is found to be of columnar type. This is in agreement with the results obtained earlier [9]. The thickness of Mo-coating is ( 3 $\mu \mathrm{m})$ found little larger than that of $\mathrm{W}$ coating is $(\sim 2 \mu \mathrm{m})$. This indicates that the growth rates are substantially high, due to which one could get very thick coatings over practicable deposition time scales, while maintaining high crystalline quality, uniformity, purity, good adhesion and reproducibility. All these features have been observed for the first time in the present studies, and would not have been possible with any other synthesis method. In the case of Alumina substrates, we got very similar results. Figure 3(a) shows FE-SEM result for virgin polycrystalline Alumina substrate. It consists of grains of size $\sim 2 \mu \mathrm{m}$. For nominally adjusted process parameters (as described earlier, in the case of $\mathrm{Si}$ substrates) one gets a cauliflower-type morphology with 


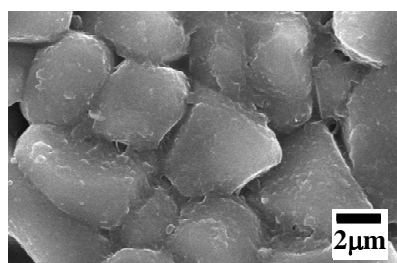

(a)

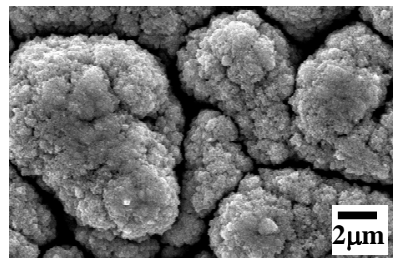

(c)

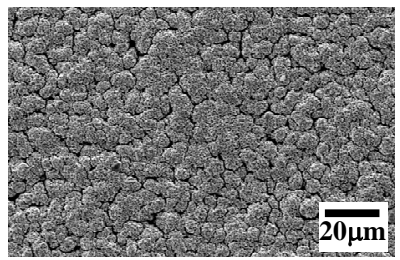

(e)

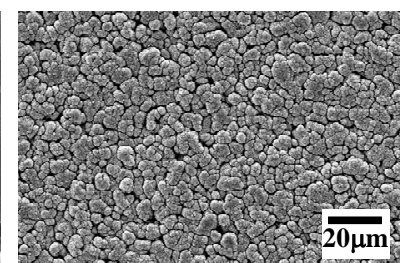

(b)

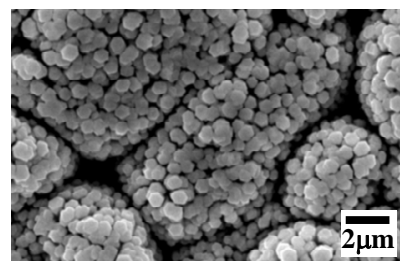

(d)

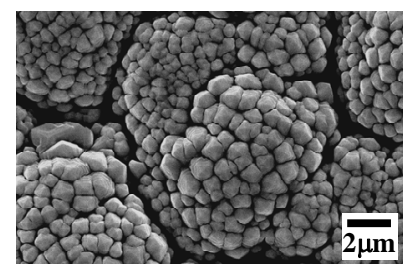

(f)
Figure 3. FE-SEM micrographs, at different magnifications, for Mo- and W-coatings on alumina substrates (a) virgin alumina substrate; (b) and (c) for Mo-coatings with nominally adjusted conditions; (d) high quality Mo-coating; (e) and (f) views for high quality of $\mathrm{W}$-coating.

substantial amount of oxygen content ( 30 - 40 at \%) (in both cases, when Mo- or W-filaments are used). The compositional and structural features of such coatings are found to be very similar to those observed in case of Si-substrates. A typical coating morphology using Mofilaments is shown in the SEM micrographs, at different magnifications, in Figures 3(b) and (c), as an example. Subsequent to the optimization of process parameters (as discussed earlier in the case of Si substrate) one gets high quality coatings of pure-Mo and pure-W. The typical results are shown in SEM micrographs of Figure 3(d) for Mo-coating and Figures 3(e) and (f), at different magnifications, for W-coatings. As can be seen, these coatings exhibit similar features to those obtained on Sisubstrates, viz. 1) Uniform coverage of coatings throughout the area of the substrate; 2) The coatings are very well faceted; 3) The particles are of hexagonal shaped in case of Mo-coating while triangular shaped in the case of W-coating; 4) The particle size, however, is smaller than that observed for Si substrate, and in both the cases (Mo and $\mathrm{W}$ ) there is very narrow size distribution. (Note that in the case $\mathrm{W}$ coating on Si substrate, a substantial size distribution was observed).

The typical EDX measurements and the glancing angle XRD on high quality coatings are depicted in Figure 4(a) for Mo-coating on Si substrate and in Figure 4(b) for

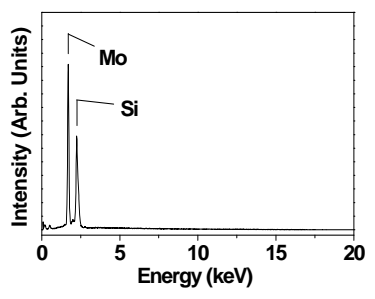

(a)

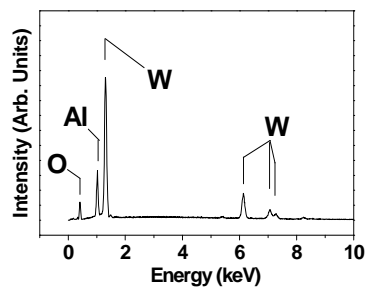

(b)

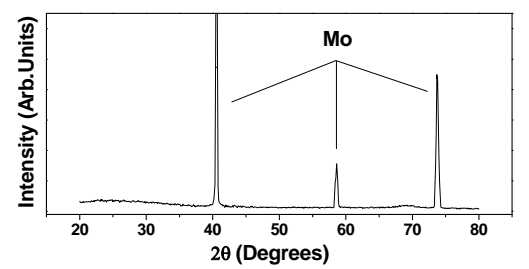

(c)

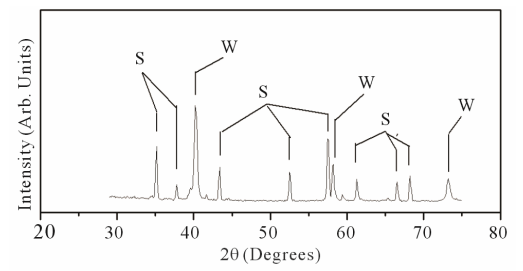

(d)

Figure 4. EDX results for (a) high quality Mo-coating on Si and (b) high quality $\mathrm{W}$-coating on alumina. The glancing angle XRD results for Mo-coating on Si and $W$-coating on alumina substrate are shown in (c) and (d) (note that oxygen peak in (b) and XRD peaks labeled by " $S$ " in (d) refer to the contributions from alumina substrate).

W-coating on Alumina substrate. The EDX results exhibit strong signals due to $\mathrm{Mo}$ and $\mathrm{W}$ in the respective cases. Note that the oxygen signal in Figure 4(b) is due to underlaying Alumina substrate and not from the overlayer W coating. We have confirmed this by carrying out EDX measurements on both types (Mo and W) of thicker coatings on Alumina substrates. In both cases, we have not observed any signal due to oxygen or any other impourity. This confirms the purity of coatings. The glancing angle (incident angle $\theta \sim 3^{\circ}$ ) X-ray diffraction pattern of Mo coating on Si substrate is shown in Figure 4(c). It shows well defined diffraction peaks at $2 \theta=40.5^{\circ}$ $(\mathrm{d}=2.22 \AA), 58.6^{\circ}(\mathrm{d}=1.57 \AA)$ and $73.6^{\circ}(\mathrm{d}=1.28 \AA)$ corresponding to $\mathrm{BCC}$ structure of Mo with lattice constant $\mathrm{a}=3.14 \AA$ [22].

These peaks correspond to $<110>$, $<200>$ and $<211>$ planes, respectively. Since both Mo and W has same BCC crystal structure with almost identical lattice parameter (Mo-3.14 $\AA, \mathrm{W}$-3.16 $\AA$ ) their X-ay diffraction patterns happen to have very little difference in the peak positions. The X-ray diffraction result for $\mathrm{W}$-coating on Alumina substrate is shown in Figure 4(d) which reveals well defined difraction peaks at $2 \theta=40.26^{\circ}(\mathrm{d}=2.238$ $\AA), 57.27^{\circ}\left(\mathrm{d}=1.58 \AA\right.$ ) and $73.2^{\circ}(\mathrm{d}=1.29 \AA)$ due, re- 
spectively, to the $\langle 110>$, $<200>$ and $<211>$ crystallographic planes of crystalline body-centered centered cubic $(\alpha-\mathrm{W})$ phase [22]. The small peaks labeled by "S" are due to alumina $\left(\alpha-\mathrm{Al}_{2} \mathrm{O}_{3}\right)$ substrate. Yet another important facet of the present method refers to the fabrication of composite coating. Figure 5 shows typical results for synthesis of thicker (deposition time $\sim 40 \mathrm{~min}$ ) coating of Mo-W composite on Si substrate.

In these studies, the $\mathrm{W}$ and Mo filaments are used simultaneously (and alternately). The SEM micrographs, at different magnifications, are shown in Figure 5(a) and (b). From the overview micrograph of Figure 5(a), it is observed that the coating is very uniform over the whole area of the substrate. The magnified view in Figure 5(b) reveals faceted particles. Each particle exhibits a mixture of hexagonal and square faces indicating simultaneous growth of Mo and W lattice. The EDX measurements, shown Figure 5(c), reveal strong contributions due to Mo and $\mathrm{W}$ with no signal from substrate (since coating is thicker) and composition of coating to be $\sim \mathrm{W}_{13} \mathrm{Mo}_{87}$. Since both Mo and W have same BCC crystal structure with almost identical lattice parameter (Mo-3.14 $\AA$, $\mathrm{W}-3.16 \AA$ ), it is expected that one would get infinite solid solubility [22]. The SEM result, however, indicates that both the metals grow separately within a given particle. So one gets a mixture of individual Mo and $\mathrm{W}$ particles, rather than each particle being a mixture of Mo and $\mathrm{W}$. The X-ray diffraction patterns happen to be very similar to that of the individual pure metals and giving peaks at $2 \theta \sim 40.5^{\circ}(\mathrm{d} \sim 2.22 \AA), 58(\mathrm{~d} \sim 1.57 \AA$ ),

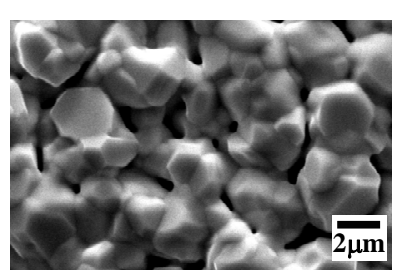

(a)

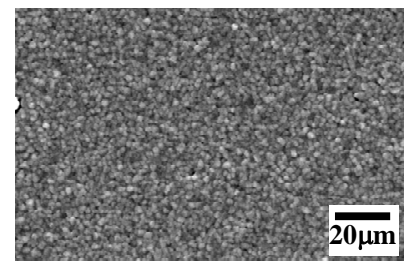

(b)

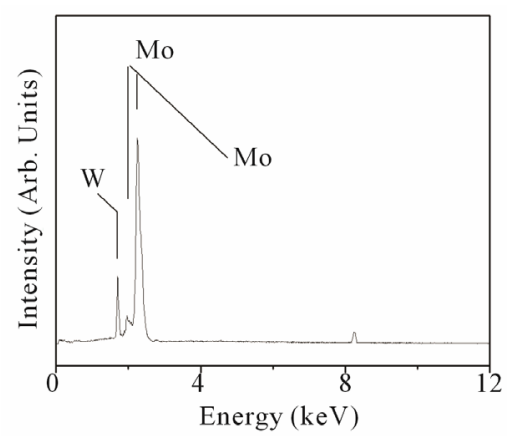

(c)

Figure 5. (a) and (b) FE-SEM micrographs, at different magnifications, corresponding to Mo-W composite coating; (c) EDX measurements on composite coating which reveal composition to be $\sim \mathrm{W}_{13} \mathrm{Mo}_{87}$. and 73.5 ( $\mathrm{d} \sim 1.28 \AA$ ) corresponding to dffraction from $<110>,<200>$ and $<211>$ planes [22]. Note that the XRD data for Mo-W composite is not available. It is also possible to change the composition of the resulting coatings by changing the number of each type of filaments. This methodology leads to the change in the total surface area exposed by each type of the filament, hence the difference in the amount of formation and sublimation of respective oxides, thus ultimately rendering different elemental compositions in the coating.

The coatings can be fabricated on larger areas also, just by giving a relative motion to the filament and the substrate holders. (e.g. X-Y motion for larger planner area, rotational motion for cylindrical substrates, linear motion for long strip/foil shaped substrate such as a "roll to roll” mechanism). In the present studies, we could get uniform depositions on over planer area of $\sim 100 \mathrm{~cm}^{2}$, and also on the rods having size $1 \mathrm{~cm}$ dia $\times 3 \mathrm{~cm}$ length. This kind of feature is not possible in conventional CVD/PVD methods, and thus, it forms yet another important aspect of the present method.

One more interesting feature of the present method refers to an "in situ" conversion of metal films in to its compounds such as a carbide, for example. After deposition of Mo or W coatings, the flow of oxygen gas in the chamber is stopped and the methane $\left(\mathrm{CH}_{4}\right)$ gas was introduced at flow rate of 5 - $10 \mathrm{sccm}$, keeping the hydrogen flow rate fixed at $100 \mathrm{sccm}$. The chamber pressure was also kept unaltered, i.e. at 30 Torr. The carburization time depends upon the thickness of the metal film (although it is a little larger than that used for deposition of the pure metal coating). The SEM result after carburization ( for $30 \mathrm{~min}$.) of $\mathrm{W}$-coating (deposited for $20 \mathrm{~min}$.) is shown in Figure 6(a). There is a little enhancement in the size of crystallites. The shape of particles is also changed to some extent although these are still faceted. The EDX result corresponding to carburization of Mo coating is shown in Figure 6(b), which now reveals a carbon contribution along with Mo (and Si from the substrate). The carbon percentage found to be $\sim 35$ at \%, indicating formation of $\mathrm{Mo}_{2} \mathrm{C}$ phase [22]. Similar results are observed in case of carburization of $\mathrm{W}$-coating. The $\mathrm{X}$-ray diffraction patterns after carburization of Mo and $\mathrm{W}$ are shown in Figures 6(c) and (d) respectively. In the former case, one gets prominent and sharp diffraction peaks (shown by solid circles) at $2 \theta=34.4^{\circ}(\mathrm{d}=2.6 \AA$ ), $37.9^{\circ}(\mathrm{d}=2.36 \AA)$ and $39.3^{\circ}(\mathrm{d}=2.28 \AA) 52.8^{\circ}(\mathrm{d}=$ 1.75), $72.4^{\circ}(\mathrm{d}=1.3), 74.7^{\circ}(\mathrm{d}=1.27)$ and $75.5^{\circ}(\mathrm{d}=$ $1.25)$ respectively due to $\langle 16,0,0\rangle,<002\rangle$, $\langle 101\rangle$, $<102>,<200>,<112>$ and $<201>$ crystallographic planes of crystalline $\alpha-\mathrm{Mo}_{2} \mathrm{C}$ (lattice constant a $=3.012$ and c $=$ 4.735) phase [22]. In the other case (carburization of $W$ ), one gets diffraction peaks (shown by solid circles) at $2 \theta$ values, viz. $31.5^{\circ}, 35.6^{\circ}, 48.3^{\circ}$ and $73.0^{\circ}$ corresponding to 


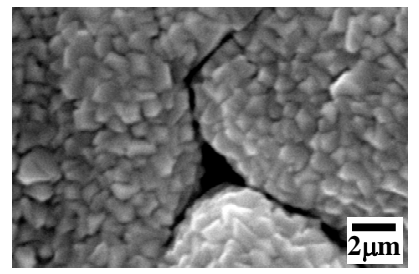

(a)

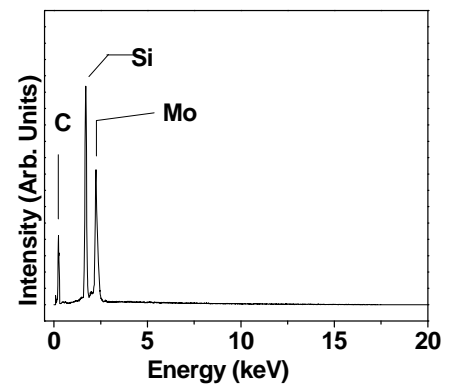

(b)

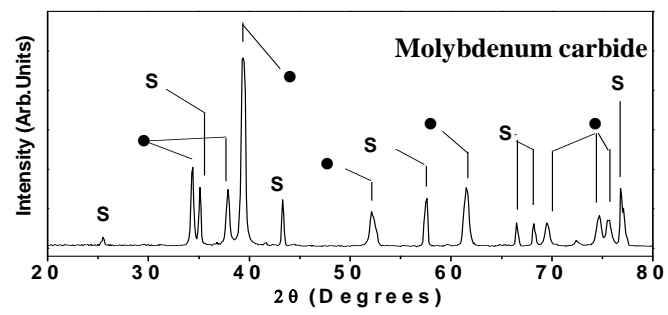

(c)

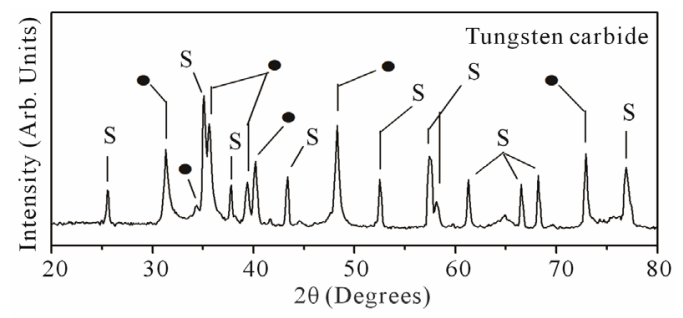

(d)

Figure 6. (a) SEM result corresponding to tungsten carbide on alumina substrate; (b) EDX result for molybdenum carbide on $<100>$ silicon substrate. The glancing angle XRD result for (c) molybdenum carbide; and (d) tungsten carbide, both on alumina substrate. (Note that the solid circles $(\bullet)$ refer to carbide peaks while peaks labeled by "S" refers to peaks due to Alumina substrate.

$<001>,<100>,<101>$, $<111>$ planes of WC phase, while small contributions at $2 \theta=34.5^{\circ}$ and $39.6^{\circ}$ (corresponding to diffraction from $<100>$ and $<101>$ planes) indicating the presence $\mathrm{W}_{2} \mathrm{C}$ phase [22]. In both the cases, the patterns reveal no peaks due to pure metal indicating a complete conversion of metal coating into their respective carbide phases. The diffraction peaks corresponding to underlying Alumina $\left(\alpha-\mathrm{Al}_{2} \mathrm{O}_{3}\right)$ substrates are also observed and these are shown by labels " $\mathrm{S}$ ", in both the patterns. The adhesion of these carbide coatings is found to be excellent as qualitatively tested by "Scotch tape" method. The approximate thumb rule calculations suggest that the carbon diffusivity (D) at the substrate temperature $\left(\mathrm{T}_{\mathrm{S}}\right) \sim 800 \mathrm{C}$ could be $\mathrm{D} \sim 10^{-11} \mathrm{~cm}^{2} / \mathrm{sec}$, (indicating four orders of magnitude decrease from its value at $\mathrm{T} \sim 1500 \mathrm{C}$ ), in both cases [1].

We have also explored the utility of these (metal and their carbides) coatings. In the first of these kinds of studies, we used these coatings as a buffer layer for fabrication of CVD-diamond coatings on copper, tool steel and stainless steel substrates. In all these cases, one gets problems in the deposition of CVD diamond. In case of copper one gets a quality growth of CVD diamond but due to very weak or no reaction at Cu-Diamod interface, the diamond coatings peel-off (due to incorporation of excessive compressive stresses due to difference in thermal expansion coefficients [23] of $\mathrm{Cu}$ and Diamond. In cases of iron based or Nickel based substrates such as Stainless Steel (SS), tool steel, Haste alloy etc. due to catalytic activity [20,23-27] of transition elements in the substrate, the precipitation and growth of graphitic/disordered carbon phases are favoured instead of a diamond phase. If a buffer layer of $\mathrm{W}$ or Mo or their carbides is used prior to diamond deposition, one can get high quality diamond coatings. Note that the CVD-diamond coating experiment is also in situ. The adhesion of such diamond coatings was also found to have much better (as qualitatively tested by "Scotch tape" method) and did not peel-off. The use of carbide layers are utilized for cutting tools (such as Taps and drills) for enhancing cutting efficiency. Figure 7(a) shows typical SEM micrograph of the diamond coating with the buffer layer on copper. Figure 7(b) shows W coating on tool steel. Figure 7(c) shows photograph of different cutting tools such as Taps, drill-bits, rimmer etc. coated by carbides. In yet another preliminary study, we fabricated patterned W-coatings on Alumina and used this pattern as a heating element. Typical patterned $\mathrm{W}$ coating (thickness $\sim 20 \mu \mathrm{m}$ ) on Alumina is shown in Figure 7(d). With the input power $30 \mathrm{~V} / 500 \mathrm{~mA}$, one gets the temperature rise beyond $500^{\circ} \mathrm{C}$, with no damage in the coating. The response time for such a temperature-rise happens to be very small, 15 sec. More detailed studies in the context of such applications are in progress in our laboratory.

\section{Conclusions}

New, simple and novel method, using HF-CVD technique, has been presented for the first time to synthesize high quality coatings of Mo, W, their carbides and composites on various types of substrates. The method is primarily based upon temperature induced "Red-ox reactions". The small amount of oxygen in the chamber gas leads to oxidation of the heated filaments. The oxide molecules reach the substrate via sublimation process. These molecules then undergo reduction process to render 


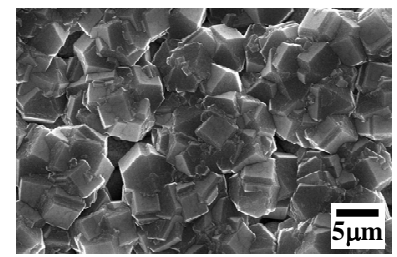

(a)

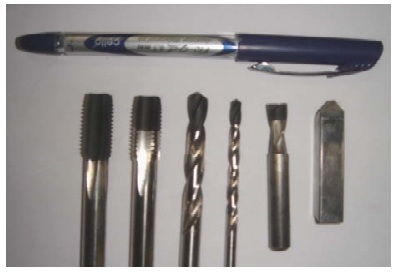

(c)

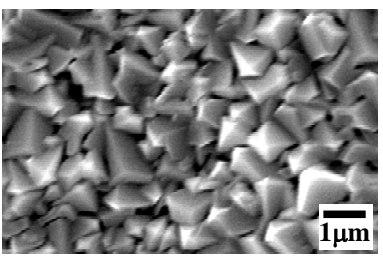

(b)

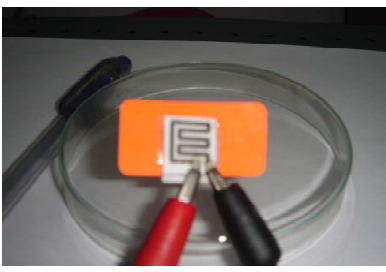

(d)
Figure 7. The results related to exploration of applications. FE-SEM micrographs corresponding to (a) CVD-diamond over layer on Mo-coated tool steel; (b) W-coated on tool steel; (c) WC and $\mathrm{Mo}_{2} \mathrm{C}$ coated cutting tools; (d) W coating on alumina patterned for its application as heater.

precipitation of the pure metal. It was necessary to optimize the processing conditions to get high quality coatings. The growth of coatings is found to be of columnar type and adhesion found to be excellent. The method offers many attractive features not rendered by conventional CVD/PVD methods. Importantly, these include 1) non-requirement of any hazardous precusors; 2) high grwoth rates; 3) compatibility to obtain coatings on larger areas. The present studies reveal that amongst different process parameters, the filament temperature $\left(T_{F}\right)$ and the composition of chamber gas are of more importance, which sensitively affect the nature of morphology and thickness of the resulting coatings. The morphological details of coating depend upon the type of the substrate. The growth of Mo particles is found to be of hexagonal shaped, while growth of $\mathrm{W}$ particles is found to have three/four sided pyramidal (or triangular) shaped geometries. In situ carburization of pure metal coatings leads to the formation of carbides (WC or $\mathrm{Mo}_{2} \mathrm{C}$ phases). The Composites of Mo-W could also be fabricated by simultaneous use of both types of filaments.

\section{Acknowledgements}

The present studies are carried out under funding from BCUD, University of Pune and the UGC-CAS programme, Department of Physics, University of Pune. RVG is grateful for the fellowship from CNQS, Department of Physics, Unversity of Pune. Help in experimentation from G. Deokar, M. Mujawar and Dr. B. Kale (from CMET, Pune) is also gratefully acknowledged.

\section{REFERENCES}

[1] D. R. Linde, "Handbook of Chemistry and Physics," 78th
Edition, CRC Press, New York, 1998, pp. 12-144, 12192-194.

[2] E. Lassner and W.-D. Schubert “Tungsten: Properties, Chemistry, and Technology of the Element, Alloys, and Chemical Compounds,” Springer, Berlin, 1999, pp. 86, 114-118.

[3] C. K Gupta, "Extractive Metallurgy of Molybdenum,” 1st Edition, CRC Press, New York, 1992.

[4] C. Porosnicu1, M. Osiac, E. Osiac and C. P. Lungu, Physics AUC, Vol. 20, Pt. 1, 2010, pp. 57-63.

[5] I. Smid, M. Akiba, G. Vieider and L. Plochl, "Development of Tungsten Armor and Bonding to Copper for PlasmaInteractive Components," Journal of Nuclear Materials, Vol. 258-263, Pt. 1, 1998, pp. 160-172.

[6] K. M. Chang, T. H. Yeh, I. C. Deng and C. W. Shih, "Amorphouslike Chemical Vapor Deposited Tungsten Diffusion Barrier for Copper Metallization and Effects of Nitrogen Addition,” Journal of Applied Physics, Vol. 82, No. 3, 1997, pp. 1469-1475. doi:10.1063/1.365925

[7] J. S. Becker and R. G. Gordon, "Diffusion Barrier Properties of Tungsten Nitride Films Grown by Atomic Layer Deposition from Bis(Tert-Butylimido)Bis(Dimethylamido) Tungsten and Ammonia,” Applied Physics Letters, Vol. 82, No. 14, 2003, 7 Pages. doi:10.1063/1.1565699

[8] N. P. Padture, et al., "Towards Durable Thermal Barrier Coatings with Novel Microstructures Deposited by Solution-Precursor Plasma Spray,” Acta Materialia, Vol. 49, No. 12, 2001, pp. 2251-2257. doi:10.1016/S1359-6454(01)00130-6

[9] M. Tabbal, M. Meunier, R. Izquierdo, B. Beau and A. Yelon, "Laser-Chemical Vapor Deposition of W Schottky Contacts on GaAs Using WF6 and $\mathrm{SiH}_{4}$," Journal of Applied Physics, Vol. 81, No. 10, 1997, pp. 6607-6611. doi:10.1063/1.365199

[10] K. M. Chang, T. H. Yeh, I. C. Deng and C. W. Shih, "Amorphouslike Chemical Vapor Deposited Tungsten Diffusion Barrier for Copper Metallization and Effects of Nitrogen Addition,” Journal of Applied Physics, Vol. 82, No. 3, 1997, pp. 1469-1475. doi:10.1063/1.365925

[11] K. Aryal, H. Khatri, R. W. Collins and S. Marsillac, "In Situ and ex Situ Studies of Molybdenum Thin Films Deposited by rf and dc Magnetron Sputtering as a Back Contact for CIGS Solar Cells," International Journal of Photo Energy, Vol. 2012, 2012, Article ID: 723714, 7 Pages.

[12] A. A. Rouse, J. B. Bemhard, E. D. Sosa and D. E. Golden, "Field Emission from Molybdenum Carbide," Applied Physics Letters, Vol. 76, No. 18, 2000, pp. 2583-2585. doi:10.1063/1.126415

[13] E. Weigert, M. Humbert, Z. J. Mellinger, Q. Ren, T. P. Beebe, L. Bao and J. Chen, "Physical Vapor Deposition Synthesis of Tungsten Monocarbide (WC) Thin Films on Different Carbon Substrates,” Journal of Vacuum Science and Technology, Vol. 26, No. 1, 2008, pp. 23-28. doi:10.1116/1.2806941

[14] V. Fox, J. Hampshire and D. Teer, " $\mathrm{MoS}_{2} /$ Metal Composite Coatings Deposited by Closed-Field Unbalanced Magnetron Sputtering: Tribological Properties and Indus- 
trial Uses,” Surface Coating Technology, Vol. 112, No. 1-3, 1999, pp. 118-122. doi:10.1016/S0257-8972(98)00798-1

[15] O. Smorygo, S. Voronin, P. Bertrand and I. Smurov, "Fabrication of Thick Molybdenum Disulphide Coatings by Thermal-Diffusion Synthesis," Tribology Letters, Vol. 17, No. 4, 2004, pp. 723-726. doi:10.1007/s11249-004-8079-8

[16] H. Zhang and D. Y. Li, "Effects of Sputtering Condition on Tribological Properties of Tungsten Coatings," Wear, Vol. 255, No. 7, 2003, pp. 924-932.

[17] P. S. Pokhre, C. Simion, V. Teodorescu, N. Barsan and U. Weimar, "Synthesis, Mechanism, and Gas-Sensing Application of Surfactant Tailored Tungsten Oxide Nanostructures," Advanced Functional Materials, Vol. 19, No. 11, 2009, pp. 1767-1774. doi:10.1002/adfm.200801171

[18] Y. Djaoued, S. Balaji and R. Brüning, "Electrochromic Devices Based on Porous Tungsten Oxide Thin Films," Journal of Nanomaterials, Vol. 2012, 2012, Article ID: 674168, 9 Pages.

[19] C. A. Ellefson, O. Marin-Flores, S. Ha and M. G. Norton, "Synthesis and Applications of Molybdenum (IV) Oxide," Journal of Materials Science, Vol. 47, No. 5, 2012, pp. 2057-2071.

[20] R. F. Davis, “Diamond Films and Coatings,” Noyes Publications, New Jersey, 1993.

[21] K. E. Spear and J. P. Dismukes, "Synthetic Diamond: Emerging CVD Science and Technology,” A Wiley-Interscience Publication, John Wiley \& Sons, Inc., New
York, 1994.

[22] International Center for Diffraction Data (PCPDFWIN), "v 1.3, JCPDS-Card nos. 04-0806 (for W), 42-1120 (for Mo), 45-0167 for $\mathrm{WO}_{3-\mathrm{x}}$, 41-0905 for $\mathrm{WO}_{3}$, 47-1319 for $\beta-\mathrm{W}, 25-1047$ (for WC), 35-0787 (for $\alpha-\mathrm{Mo}_{2} \mathrm{C}$ ) and 35-0776 (for $\alpha-\mathrm{W}_{2} \mathrm{C}$ ),” 1997.

[23] V. P. Godbole, R. J. Narayan, X. Zu, J. Narayan and J. Sankar, "Diamond Films and Composites on CobaltChromium Alloys,” Material Science and Engineering: B, Vol. 58, No. 3, 1999, pp. 251-257. doi:10.1016/S0921-5107(98)00430-9

[24] V. P. Godbole, K. Jagannadhem and J. Narayan, "Nucleation and Growth of Diamond Films on Aluminum Nitride Coated Nickel,” Applied Physics Letters, Vol. 67, No. 9, 1995, pp. 1322-1324. doi:10.1063/1.114527

[25] V. P. Godbole and J. Narayan, "Synthesis of Diamond Films on Hastelloy," Journal of Material Research, Vol. 7, No. 10, 1992, pp. 2758-2790. doi:10.1557/JMR.1992.2785

[26] V. P. Godbole and J. Narayan, "Nucleation and Growth of Diamond on FeSi2/Si Substrates by Hot Filament Chemical Vapor Deposition," Journal of Applied Physics, Vol. 71, No. 10, 1992, pp. 4944-4948. doi:10.1063/1.351380

[27] J. Narayan, V. P. Godbole, G. Matera and R. K. Singh, Journal of Applied Physics, Vol. 71, No. 2. 